\title{
Less invasive versus conventional double-valve surgery: A propensity-matched comparison
}

\author{
Fernando A. Atik, MD, ${ }^{\text {a }}$ Lars G. Svensson, MD, PhD, FACC, ${ }^{\text {a }}$ Eugene H. Blackstone, MD, FACC, a,b \\ A. Marc Gillinov, MD, FACC, ${ }^{\mathrm{a}}{ }^{\mathrm{J}}$ Jeevanantham Rajeswaran, MSc, ${ }^{\mathrm{b}}$ and Bruce W. Lytle, MD, FACC ${ }^{\mathrm{a}}$
} Objective: Less invasive approaches to double-valve surgery are used for improved cosmesis; however, few
studies have investigated their effect on outcome. We sought to compare these less invasive approaches with
conventional full sternotomy.

\begin{abstract}
Methods: From January 1995 to January 2004, 114 patients underwent primary double-valve surgery through a less invasive approach and 381 through conventional sternotomy. Because there were important differences in the patients' characteristics, a propensity score based on 42 factors was used to obtain 81 well-matched patient pairs ( $71 \%$ of possible matches) for comparison of in-hospital morbidity and mortality, mediastinal drainage, transfusion requirements, pulmonary function, pain, and long-term survival.
\end{abstract}

Results: In-hospital mortality was similar for propensity-matched patients: 6.2\% (5/81) for those undergoing less invasive surgery and $2.5 \%(2 / 81)$ for those undergoing conventional sternotomy $(P>.4)$. Occurrences of stroke $(P>.9)$, renal failure $(P=.4)$, myocardial infarction $(P>.9)$, and infection $(P>.9)$ were also similar. However, 24-hour mediastinal drainage was less after less invasive surgery (median, $250 \mathrm{vs} 400 \mathrm{~mL} ; P<$ $.0001)$, but a similar proportion of patients received transfusions $(28 \%$ vs $40 \%, P=.2)$. An equivalent proportion of patients were extubated in the operating room ( $7.7 \%$ vs $7.0 \%, P>.9)$, and median hours to extubation were similar (5.0 vs 6.5 hours). Pain scores were equivalent $(P>.3)$. Long-term survival was also similar ( $82 \%$ and $76 \%$ at 10 years, $P=.07)$.

Conclusions: Within that portion of the spectrum of double-valve surgery in which propensity matching was possible, less invasive surgery had cosmetic and blood product use advantages over conventional surgery and no apparent detriments. (J Thorac Cardiovasc Surg 2011;141:1461-68)

Supplemental material is available online.

Less invasive valve surgery can be performed through a variety of approaches, such as partial upper sternotomy, ${ }^{1-7}$ partial lower sternotomy, ${ }^{3}$ transverse sternotomy, right parasternal thoracotomy, ${ }^{4}$ right minithoracotomy with videoassisted thoracoscopy, ${ }^{8,9}$ and totally robotic surgery. ${ }^{5,8}$ Large experience with these techniques in many centers ${ }^{9-12}$ has proved their safety, efficacy, and potential benefits

\footnotetext{
From the Center for Aortic Surgery and the Marfan and Connective Tissue Disorder Clinic, Heart and Vascular Institute, Department of Thoracic and Cardiovascular Surgery, ${ }^{\mathrm{a}}$ and Research Institute, Department of Quantitative Health Sciences, ${ }^{\mathrm{b}}$ Cleveland Clinic, Cleveland, Ohio.

Supported in part by the Kenneth Gee and Paula Shaw, PhD, Chair in Heart Research (to E.H.B.) and the Judith Dion Pyle Chair in Heart Valve Research (to A.M.G.).

Disclosures: Dr Gillinov is a consultant to Edwards Lifesciences, St Jude Medical, and Medtronic.

Received for publication Oct 29, 2008; revisions received Feb 5, 2010; accepted for publication May 5, 2010; available ahead of print Nov 1, 2010.

Address for reprints: Lars G. Svensson, MD, PhD, Cleveland Clinic, Department of Thoracic and Cardiovascular Surgery, 9500 Euclid Ave/Desk J4-1, Cleveland, OH 44195 (E-mail: svenssl@ccf.org).

$0022-5223 / \$ 36.00$

Copyright (c) 2011 by The American Association for Thoracic Surgery doi:10.1016/j.jtcvs.2010.05.053
}

compared with conventional sternotomy in treating isolated mitral or aortic valve disease. Whether combined surgical intervention on both aortic and mitral valves through a less invasive approach has an advantage or even a disadvantage is unclear, and a randomized trial is unlikely. Therefore, we performed a propensity-matched comparison of in-hospital outcomes and long-term survival in patients who underwent less invasive combined mitral and aortic valve surgery with those who had conventional full sternotomy.

\section{MATERIALS AND METHODS \\ Patients}

From January 1995 to January 2004, 495 patients underwent primary combined aortic and mitral valve surgery (Table 1) with or without tricuspid valve repair at Cleveland Clinic. Patients undergoing concomitant coronary artery bypass grafting, ablation surgery for atrial fibrillation, or reoperation were excluded, as were those with endocarditis. Less invasive surgery was performed in $114(23 \%)$ patients, and conventional full sternotomy was performed in $381(77 \%)$ patients. Unmatched mean age was $59 \pm 14$ years among patients undergoing less invasive surgery and $62 \pm$ 15 years among patients undergoing conventional surgery, with nearly equal sex distribution (Table 2).

Data were in part retrieved from the prospective Cardiovascular Information Registry and in part from each patient's medical record. These data were approved for use in research by the institutional review board, with patient consent waived. 


\section{Abbreviations and Acronyms \\ $\mathrm{CL}=$ confidence limit \\ $\mathrm{FEV}_{1}=$ forced expiratory volume in 1 second}

\section{Surgical Technique}

Two less invasive approaches were included in this study. From 1995 through 1996, a right paramedian incision was used that included division of the third and fourth costal cartilages $\left(9[7.9 \% \text { ] patients })^{1}\right.$; from 1997 onward, this changed to a J incision beginning at the sternal notch and ending at the fourth intercostal space (105 [92\%] patients). ${ }^{6,7}$ With these less invasive chest-wall incisions, the mitral valve was accessed through a transseptal incision and the aortic valve through an aortic "hockey stick" incision.

Conventional general anesthesia was used in all patients regardless of surgical approach. In those undergoing full median sternotomy, the mitral valve was usually visualized by means of an incision in the left atrium anterior to the right pulmonary veins and the aortic valve through a "hockey stick" aortic incision. Patients who underwent less invasive surgery had a 3- to 4-inch (8- to 10-cm) skin incision. ${ }^{1,6,10}$

Vacuum-assisted cardiopulmonary bypass with central cannulation was used in all patients. ${ }^{13}$ Intraoperative transfusions, anesthetic technique, and timing of extubation were at the anesthesiologist's discretion. Intraoperative and postoperative transfusion and extubation were not derived from strict protocols. In the early phase of this study, there was a learning curve involved in developing the technique, which was, however, technically similar to conventional sternotomy.

\section{Study Design}

A number of differences in patients' characteristics precluded direct comparison of outcomes (Table 2). Therefore, to reduce the influence of selection, we used propensity matching to approximate a randomized trial. ${ }^{14-16}$ In the spirit of such a trial, we followed the intent-to-treat principle, such that the $11(9.6 \%)$ patients with an intended less invasive approach who were converted to conventional sternotomy were retained for analysis in the less invasive group, as they would be in a randomized clinical trial. Initially, a parsimonious model based on variables in Appendix 1 was formulated by means of logistic regression analysis using bagging for variable selection (see Table E1) to understand the drivers of patient selection. ${ }^{17}$ To this model were added nonsignificant variables to form a propensity model. From this, a propensity score was generated for each patient from a logistic regression model $(\mathrm{C}=0.81)$ based on 42 preoperative variables and procedure variables predictable preoperatively (Appendix 1). Greedy matching based on the propensity score was used to identify 81 patient pairs for comparison (Table 2), $71 \%$ of all possible matches. ${ }^{18}$ Figure 1 indicates that the propensity-matched patients are drawn from across the entire spectrum of propensity. However, unmatched patients (see Table E2) are predominantly those for whom conventional sternotomy was rather systematically applied. Clearly, as seen from the figure, there is good overlap between the procedures after propensity adjustment. This strategy was repeated for the 2000-2004 cohort with spirometry and pain scores, yielding 43 propensity-matched patient pairs.

\section{Outcomes}

Outcomes assessed included intraoperative support (myocardial ischemic time and cardiopulmonary bypass time), postoperative in-hospital mortality and morbidity (defined in accordance with the Society of Thoracic Surgeons National Database: http://www.ctsnet.org/file/rptDataSpecifications252_1_ ForVendorsPGS.pdf), blood product use, mediastinal drainage at 6 and 24 hours, hematocrit value at hospital discharge, time to extubation (which was at the discretion of attending anesthesiologists in either the operating room or intensive care unit), all incentive spirometry values after extubation, all pain scores, length of hospital stay, and long-term survival.

Spirometry and pain scoring were performed and results recorded from January 2000 to January 2004. Both spirometric values and pain scores were obtained routinely, as part of clinical care, from all patients after surgical intervention. Spirometry, consisting of forced expiratory volume in 1 second $\left(\mathrm{FEV}_{1}\right.$; in milliliters), was performed periodically by respiratory therapists using a Renaissance II bedside spirometer (Puritan Bennett, Carlsbad, Calif) until hospital discharge; a total of 385 values were available for 31 of the 43 matched patients undergoing a less invasive procedure and 34 of the 43 patients undergoing conventional surgery. FEV values $_{1}$ were normalized to percent predicted values by the National Health and Nutrition Examination Survey algorithm. ${ }^{19}$ Pain intensity, ranging from 0 (none) to 10 (severe), was recorded by nursing staff from the patients' arrival in the intensive care unit to hospital discharge by using the extensively validated Wong-Baker visual analog scale. ${ }^{20,21}$ A total of 3337 pain scores were available for $33(77 \%)$ of the 43 patients undergoing less invasive surgery and 36 (84\%) of the 43 patients undergoing conventional surgery.

Survival was assessed based on follow-up every 2 years by using an institutional review board-approved questionnaire supplemented by the Social Security Death Index. ${ }^{22,23}$ For matched patients undergoing less invasive surgery, 291 patient-years of follow-up were available for analyses, mean follow-up was $3.6 \pm 2.4$ years, and $10 \%$ were followed for more than 7.3 years. In the matched cohort undergoing conventional sternotomy, 297 patient-years of follow-up were available for analyses, mean follow-up was $3.7 \pm 2.1$ years, and $10 \%$ were followed for more than 6.5 years.

\section{Comparisons}

Categorical outcomes were compared by using either the $\chi^{2}$ or Fisher's exact test and continuous outcomes by using the Wilcoxon rank-sum nonparametric test. To compare temporal patterns of postoperative $\mathrm{FEV}_{1}$ across time, the repeated continuous values were analyzed longitudinally by using mixed-model regression, ${ }^{18}$ with autoregressive order 1 correlation structure to accommodate the correlated nature of the observations within each patient.

To compare temporal patterns of postoperative pain across time, pain scores were combined into 5 categories because of the low frequency of higher scores: 0 (pain score 0), 1 (pain scores 1-3), 2 (pain scores 4-6), 3 (pain scores 7 and 8), and 4 (pain scores 9 and 10). The pain-score category was analyzed longitudinally by using a nonlinear cumulative logit mixed model for repeated measures that resolved a number of temporal components and their shaping parameters ${ }^{24}$ in the cumulative odds domain. Each component was independently modulated by a time function with common random intercept. Survival was compared nonparametrically by using the Kaplan-Meier method and parametrically by using a temporal decomposition model. ${ }^{24}$

\section{Presentation}

Categorical variables are summarized as frequencies and percentages and continuous variables as means \pm standard deviations or as equivalent 15 th, 50th (median), and 85th percentiles when data were skewed. Asymmetric confidence limits (CLs) are equivalent to \pm 1 standard deviation $(68 \%)$. All analyses were performed with SAS statistical software version 9.1 (SAS Institute, Inc, Cary, NC).

\section{RESULTS}

\section{Intraoperative Support}

Among propensity-matched patients, intraoperative myocardial ischemic time was shorter with less invasive surgery ( $86 \pm 23$ vs $97 \pm 33$ minutes, $P=.02$ ) than with conventional sternotomy, as was cardiopulmonary bypass time $(105 \pm 32$ vs $124 \pm 47$ minutes, $P=.004)$. 
TABLE 1. Overall distribution of double-valve operations by surgical approach

\begin{tabular}{|c|c|c|c|c|}
\hline \multirow[b]{3}{*}{ Operation } & \multicolumn{2}{|c|}{ Overall } & \multicolumn{2}{|c|}{ Propensity matched } \\
\hline & Less invasive & Conventional & Less invasive & Conventional \\
\hline & No. $(\%$ of 114$)$ & No. $(\%$ of 381$)$ & No. $(\%$ of 81$)$ & No. $(\%$ of 81$)$ \\
\hline $\mathrm{MV}+\mathrm{AV}$ repair & $36(32)$ & $34(8.9)$ & $16(20)$ & $16(20)$ \\
\hline $\mathrm{MV}+\mathrm{AV}+\mathrm{TV}$ repair & $3(2.6)$ & $6(1.6)$ & $2(2.5)$ & $0(0)$ \\
\hline $\mathrm{MV}+\mathrm{AV}$ replacement & $27(24)$ & $131(34)$ & $25(31)$ & $25(31)$ \\
\hline $\mathrm{MV}+\mathrm{AV}$ replacement $+\mathrm{TV}$ repair & $5(4.4)$ & $51(13)$ & $5(6.2)$ & $5(6.2)$ \\
\hline $\mathrm{MV}+\mathrm{AV}+\mathrm{TV}$ replacement & $0(0)$ & $1(0.26)$ & $0(0)$ & $1(1.2)$ \\
\hline $\mathrm{MV}$ replacement $+\mathrm{AV}$ repair & $1(0.88)$ & $3(0.79)$ & $0(0)$ & $1(1.2)$ \\
\hline $\mathrm{MV}$ repair $+\mathrm{AV}$ replacement & $41(36)$ & $122(32)$ & $32(40)$ & $30(37)$ \\
\hline $\mathrm{MV}$ repair $+\mathrm{AV}$ replacement $+\mathrm{TV}$ repair & $0(0)$ & $33(8.7)$ & $0(0)$ & $3(3.7)$ \\
\hline MV replacement $+\mathrm{AV}$ and $\mathrm{TV}$ repair & $1(0.88)$ & $0(0)$ & $1(1.2)$ & $0(0)$ \\
\hline
\end{tabular}

$M V$, Mitral valve; $A V$, aortic valve; $T R$, tricuspid valve.

\section{In-Hospital Mortality and Morbidity}

Among propensity-matched patients, in-hospital mortality was $6.2 \%$ (5 patients; CL, $3.5 \%-10 \%$ ) in the less invasive group and $2.5 \%$ ( 2 patients; CL, $0.88 \%-5.6 \%$ ) in the conventional group $(P=.4)$. In-hospital complications occurred with similar frequency in matched groups (Table 3 ).

\section{Bleeding and Transfusion}

Return to the operating room for bleeding was similar in matched groups ( $8.6 \%$ in the less invasive group vs $4.9 \%$ in the conventional sternotomy group, $P=.5$; Table 3 ). However, mediastinal drainage was lower at 6 and 24 hours after a less invasive approach $(100 \mathrm{~mL}$ [CL, 50-320 mL] and 250

TABLE 2. Preoperative patient characteristics according to surgical approach: Overall and propensity-matched patients

\begin{tabular}{|c|c|c|c|c|c|c|c|c|c|c|}
\hline \multirow[b]{3}{*}{ Characteristic } & \multicolumn{5}{|c|}{ Overall } & \multicolumn{5}{|c|}{ Propensity matched } \\
\hline & \multicolumn{2}{|c|}{ Less invasive $(n=114)$} & \multicolumn{2}{|c|}{ Conventional $(n=381)$} & \multirow[b]{2}{*}{$P$ value } & \multicolumn{2}{|c|}{ Less Invasive $(\mathbf{n}=\mathbf{8 1})$} & \multicolumn{2}{|c|}{ Conventional $(n=81)$} & \multirow[b]{2}{*}{$\begin{array}{c}P \\
\text { valu }\end{array}$} \\
\hline & No.* & $\begin{array}{l}\text { No. }(\%) \text { or } \\
\text { mean } \pm \text { SD }\end{array}$ & No.* & $\begin{array}{l}\text { No. }(\%) \text { or } \\
\text { mean } \pm \text { SD }\end{array}$ & & No.* & $\begin{array}{l}\text { No. }(\%) \text { or } \\
\text { mean } \pm \text { SD }\end{array}$ & No.* & $\begin{array}{l}\text { No. }(\%) \text { or } \\
\text { mean } \pm \text { SD }\end{array}$ & \\
\hline \multicolumn{11}{|l|}{ Demography } \\
\hline Female sex & 114 & $48(42)$ & 381 & $197(52)$ & .07 & 81 & $34(42)$ & 81 & $32(40)$ & .7 \\
\hline Age (y) & 114 & $59 \pm 14$ & 381 & $62 \pm 15$ & .01 & 81 & $59 \pm 16$ & 81 & $60 \pm 16$ & .7 \\
\hline BMI $\left(\mathrm{kg} \cdot \mathrm{m}^{-2}\right)$ & 114 & $25 \pm 3.7$ & 381 & $27 \pm 6.1$ & .004 & 81 & $25 \pm 3.9$ & 81 & $25 \pm 4.2$ & .7 \\
\hline \multicolumn{11}{|l|}{ Cardiac comorbidity } \\
\hline NYHA functional class & 114 & & 381 & & $<.0001$ & 81 & & 81 & & .9 \\
\hline I & & $18(16)$ & & $37(9.7)$ & & & $14(17)$ & & $11(14)$ & \\
\hline II & & $75(66)$ & & $180(47)$ & & & $48(59)$ & & $52(64)$ & \\
\hline III & & $18(16)$ & & $124(33)$ & & & $16(20)$ & & $16(20)$ & \\
\hline IV & & $3(2.6)$ & & $40(11)$ & & & $3(3.7)$ & & $2(2.5)$ & \\
\hline $\operatorname{LVEF}(\%)$ & 107 & $55 \pm 9.4$ & 309 & $50 \pm 14$ & .008 & 74 & $54 \pm 10$ & 73 & $54 \pm 10$ & 6 \\
\hline MV regurgitation & 113 & & 377 & & .004 & 80 & & 80 & & 6 \\
\hline Moderately severe (3+) & & $25(22)$ & & $123(33)$ & & & $21(26)$ & & $20(25)$ & \\
\hline Severe $(4+)$ & & $65(58)$ & & $155(41)$ & & & $43(54)$ & & $42(53)$ & \\
\hline MV stenosis & 112 & $30(27)$ & 364 & $110(30)$ & .5 & 79 & $22(28)$ & 81 & $23(28)$ & .9 \\
\hline AV regurgitation & 114 & & 366 & & .1 & 81 & & 80 & & $>.9$ \\
\hline Moderately severe (3+) & & $34(30)$ & & $88(24)$ & & & $21(26)$ & & $20(25)$ & \\
\hline Severe (4+) & & $35(31)$ & & $102(28)$ & & & $29(36)$ & & $31(39)$ & \\
\hline AV stenosis & 113 & $45(40)$ & 367 & $226(62)$ & $<.0001$ & 80 & $37(46)$ & 80 & $40(50)$ & .6 \\
\hline TV regurgitation & 112 & & 340 & & $<.0001$ & 79 & & 78 & & $>.9$ \\
\hline Severe (4+) & & $2(1.8)$ & & $30(8.8)$ & & & $2(2.5)$ & & $2(2.6)$ & \\
\hline Atrial fibrillation/flutter & 114 & $18(16)$ & 381 & $82(22)$ & .2 & 81 & $13(16)$ & 81 & $13(16)$ & 1.0 \\
\hline \multicolumn{11}{|l|}{ Noncardiac comorbidity } \\
\hline Endocarditis & 114 & $8(7)$ & 381 & $25(6.6)$ & .9 & 81 & $6(7.4)$ & 81 & $10(12)$ & .3 \\
\hline COPD & 109 & $10(9.2)$ & 319 & $110(34)$ & $<.0001$ & 76 & $9(12)$ & 77 & $7(9.1)$ & 6 \\
\hline Hypertension & 110 & $42(38)$ & 361 & $186(52)$ & .01 & 79 & $32(41)$ & 78 & $33(42)$ & .8 \\
\hline Treated diabetes & 112 & $3(2.7)$ & 370 & $41(11)$ & .007 & 80 & $3(3.8)$ & 80 & $4(5.0)$ & $>.9$ \\
\hline Creatinine $\left(\mathrm{mg} \cdot \mathrm{dL}^{-1}\right)$ & 111 & $0.7 / 0.9 / 1.2 \dagger$ & 375 & $0.7 / 1.0 / 1.4 \dagger$ & .01 & 79 & $0.7 / 1.0 / 1.3 \dagger$ & 79 & $0.7 / 1.0 / 1.3 \dagger$ & .9 \\
\hline
\end{tabular}

$S D$, Standard deviation; $B M I$, body mass index; $N Y H A$, New York Heart Association; $L V E F$, left ventricular ejection fraction; $M V$, mitral valve; $A V$, aortic valve; $T V$, tricuspid valve; $C O P D$, chronic obstructive pulmonary disease. $*$ Patients with data available. $\uparrow 15$ th $/ 50$ th $/ 85$ th percentiles. 


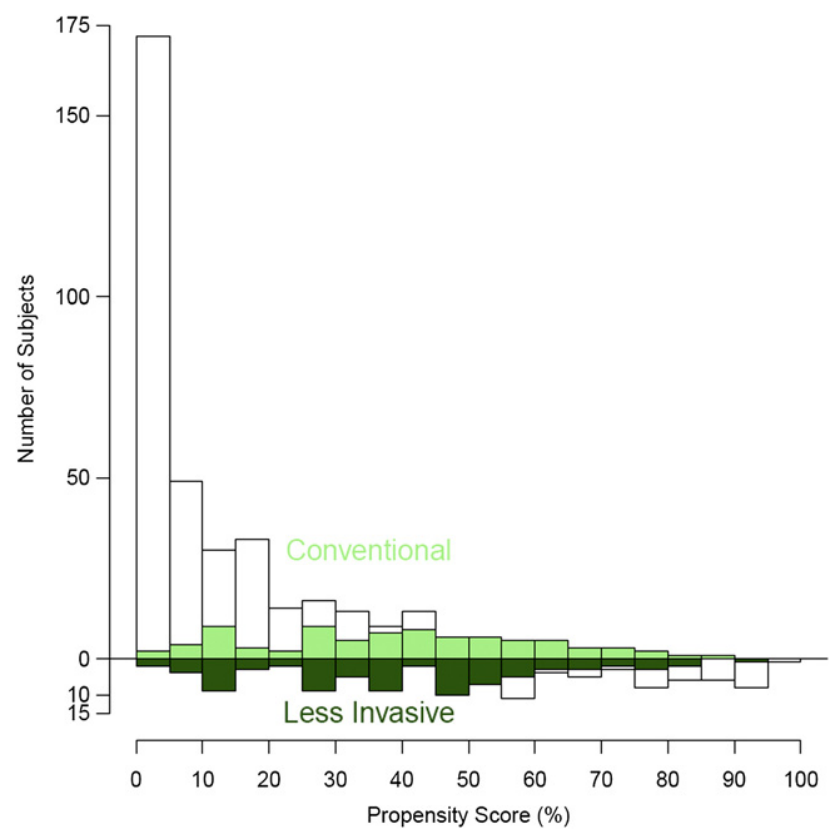

FIGURE 1. Mirrored histogram of distribution of propensity scores for conventional (bars above zero line) and less invasive (bars below zero line) approaches. The darkened area represents matched patient pairs, showing that they cover the complete spectrum of cases.

$\mathrm{mL}$ [CL, 143-505 $\mathrm{mL}]$ ) than after conventional sternotomy (250 $\mathrm{mL}$ [CL, 150-342 $\mathrm{mL}$ ] and $400 \mathrm{~mL}$ [CL, 250-628 $\mathrm{mL}], P<.0001)$. Transfusion was equivalent in the matched groups. Hematocrit values at discharge were equivalent in the matched groups $(30 \% \pm 3.7 \%$ after less invasive surgery and $30 \% \pm 3.8 \%$ after conventional surgery, $P=.7$ ).

\section{Respiratory Function}

An equivalent proportion of matched patients were extubated in the operating room after less invasive surgery and conventional sternotomy $(7.7 \%$ vs $7.0 \%, P>.9)$. Median hours to extubation were also equivalent (5 hours [CL, 3.2-11 hours] vs 6.5 hours [CL, 3.2-17 hours], $P=.2$ ). In matched patients, a pattern of higher $\mathrm{FEV}_{1}$ was observed immediately after extubation among those undergoing less invasive surgery; however, $\mathrm{FEV}_{1}$ became similar in the 2 groups after the first 12 hours (Figure 2).

\section{Postoperative Pain}

The general temporal pattern of pain-score categories among all matched patients is shown in Figure 3, A. Over the first 24 postoperative hours, only about a third of the patients were pain free, and this proportion increased to about $65 \%$ by day 3 and stabilized. Pain scores were similar after less invasive surgery and conventional sternotomy $(P>.3$; Figure 3, B).

\section{Length of Stay}

Among matched patients, median postoperative length of stay was similar (7 days [CL, 5-12 days] after less invasive surgery and 7 days [CL, 5-13 days] after conventional sternotomy, $P>.9$ ).

\section{Survival}

Among matched patients, survival at 1, 5, and 8 years was $89 \%, 85 \%$, and $82 \%$ after less invasive surgery and $94 \%$, $83 \%$, and $76 \%$ after conventional sternotomy $(P=.9$, Figure 4).

TABLE 3. In-hospital outcomes by surgical approach, overall and in propensity-matched patients

\begin{tabular}{|c|c|c|c|c|c|c|c|c|c|c|}
\hline \multirow[b]{3}{*}{ Outcome } & \multicolumn{5}{|c|}{ Overall } & \multicolumn{5}{|c|}{ Propensity matched } \\
\hline & \multicolumn{2}{|c|}{ Less invasive $(n=114)$} & \multicolumn{2}{|c|}{ Conventional $(n=381)$} & \multirow[b]{2}{*}{$P$ value } & \multicolumn{2}{|c|}{ Less invasive $(n=81)$} & \multicolumn{2}{|c|}{ Conventional $(n=81)$} & \multirow{2}{*}{$\begin{array}{c}P \\
\text { value } \\
\end{array}$} \\
\hline & No. & $\%$ & No. & $\%$ & & No. & $\%$ & No. & $\%$ & \\
\hline Death & 5 & 4.4 & 15 & 3.9 & .8 & 5 & 6.2 & 2 & 2.5 & .4 \\
\hline Return to OR for bleeding & 9 & 7.9 & 24 & 6.3 & .5 & 7 & 8.6 & 4 & 4.9 & .5 \\
\hline Stroke & 3 & 2.6 & 8 & 2.1 & .7 & 2 & 2.5 & 2 & 2.5 & 1.0 \\
\hline Renal failure & 4 & 3.5 & 14 & 3.7 & 1.0 & 4 & 4.9 & 1 & 1.2 & .4 \\
\hline Respiratory insufficiency & 6 & 5.3 & 36 & 9.5 & .2 & 6 & 7.4 & 5 & 6.2 & .8 \\
\hline Septicemia/sepsis & 4 & 3.5 & 13 & 3.4 & 1.0 & 3 & 3.7 & 4 & 4.9 & $>.9$ \\
\hline $\mathrm{AF}$ requiring treatment & 70 & 61 & 230 & 60 & .8 & 53 & 65 & 48 & 59 & .5 \\
\hline $\begin{array}{l}\text { Heart block (requiring } \\
\text { permanent pacemaker) }\end{array}$ & 3 & 2.6 & 19 & 5.0 & .4 & 2 & 2.5 & 4 & 4.9 & .7 \\
\hline Myocardial infarction & 2 & 1.8 & 2 & 0.52 & .2 & 2 & 2.5 & 1 & 1.2 & $>.9$ \\
\hline RBC transfusion & $26 / 111 *$ & 23 & $190 / 347$ & 55 & $<.0001$ & $22 / 78 *$ & 28 & $31 / 78 *$ & 40 & .2 \\
\hline Deep sternal wound infection & 1 & 0.88 & 3 & 0.19 & 1.0 & 1 & 1.2 & 0 & 0 & $>.9$ \\
\hline ICU stay (d) & $1 / 1 / 3 \dagger$ & - & $1 / 2 / 5 \dagger$ & $1 / 2 / 5 \dagger$ & $<.0001$ & $1 / 1 / 3 \dagger$ & - & $1 / 1 / 3 \dagger$ & - & .9 \\
\hline Hospital stay (d) & $5 / 7 / 12 \dagger$ & - & $6 / 9 / 19 \dagger$ & $6 / 9 / 19 \dagger$ & $<.0001$ & $5 / 7 / 15 \dagger$ & - & $5 / 7 / 15 \dagger$ & - & 6 \\
\hline
\end{tabular}

$O R$, Operating room; $A F$, atrial fibrillation; $R B C$, red blood cell; $I C U$, intensive care unit. *Number of patients with data available. $\dagger 15$ th/50th/85th percentiles. 


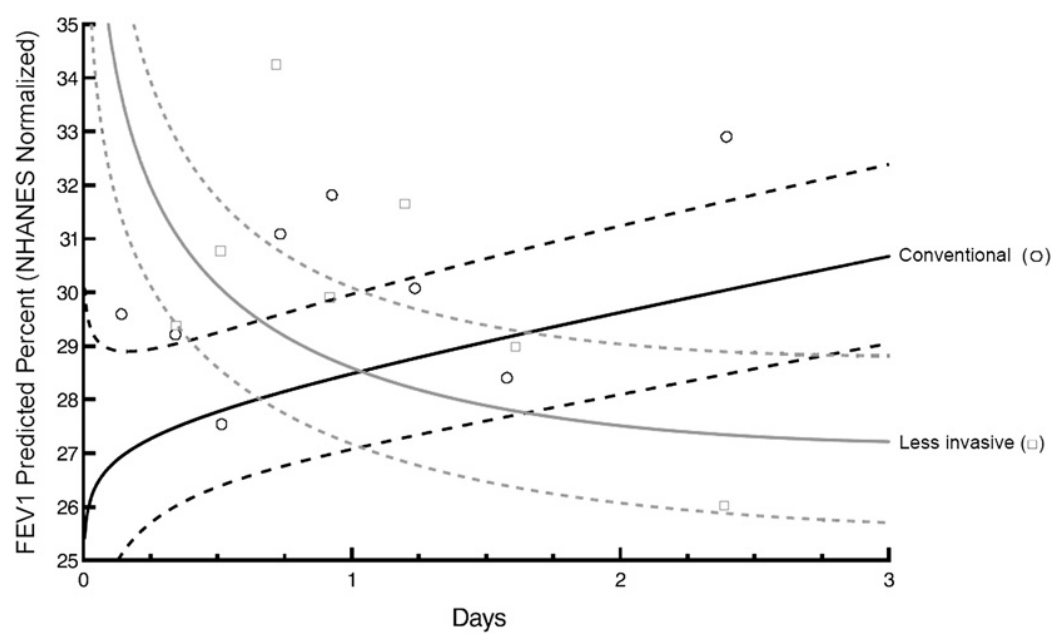

FIGURE 2. Temporal pattern of postextubation forced expiratory volume in 1 second $\left(F E V_{l}\right)$ as a percentage of predicted value after less invasive and conventional double-valve surgery in propensity-matched groups. Solid lines are parametric estimates of temporal trend enclosed within dashed lines ( $68 \%$ confidence limits, equivalent to \pm 1 standard error). Symbols represent data grouped within time frames without regard for repeated assessment simply to provide crude verification of model fit. NHANES, National Health and Nutrition Examination Survey.

\section{Risk-Unadjusted Data}

Figures E1 through E3 show risk-unadjusted data for respiratory function, postoperative pain scores, and survival, corresponding to Figures 2, 3, and 4, respectively. Table 1, Figure 1, and Tables E1 and E2 demonstrate that patients and operative characteristics of those undergoing conventional sternotomy are systematically quite different from those undergoing a less invasive procedure. The propensity-matched groups represent the entire spectrum of disease, but are predominantly drawn from cases in the middle range of the propensity scale.

\section{DISCUSSION \\ Principal Findings}

Extensive experience at our institution performing limited skin incision with a J partial upper sternotomy encouraged its use for more complicated procedures, such as double- or triple-valve operations. Thus, this study was performed to compare the outcomes with conventional sternotomy. Results show that less invasive approaches did not increase the risk of primary double-valve operations, but benefits were restricted to less blood loss and a shorter cosmetic scar.

Matched cohort analysis revealed that a relatively low-risk population in their late 50 s were mildly symptomatic and had normal left ventricular function were included in the propensity analyses. In this group of patients, of note, choosing a minimal-access approach did not jeopardize use of valve repair. Not sacrificing the repair rate is important because, when indicated, outcomes of double-valve repair $^{25}$ and even mitral valve repair with aortic valve replacement ${ }^{26}$ have proved superior to those of doublevalve replacement.

Although technically more demanding, less invasive double-valve surgery did not prolong aortic clamp or cardiopulmonary bypass times. Bleeding was minimized, but this did not translate into less frequent surgical reexploration or lower transfusion requirements. However, previous series, ${ }^{1,2}$ including our propensity-matched comparison of mitral valve procedures with a larger series of patients $(n=2124)$ receiving isolated, less invasive valve surgery, have shown benefits compared with full sternotomy.

Other potential benefits relate to better pain control and improved pulmonary function, ${ }^{27,28}$ factors closely related to the speed with which patients recover and possibly shorter hospitalization, especially in the elderly. ${ }^{29}$ Indeed, in recent comparisons of less invasive surgery for either mitral or aortic valve disease, benefits in terms of blood use, respiratory function, pain scores, and hospital stay were observed. ${ }^{2}$ Our results in this study did not support these findings, but the small denominator might have limited the power to detect differences.

Long-term survival paralleled expected survival for double-valve surgery in the conventional surgery cohort, as well as outcomes reported by others. ${ }^{30,31}$ Less invasive double- or triple-valve surgery is not ideal, however, in more complex patients with extensive calcification of the base of the heart, active endocarditis with annular invasion and abscess, or need to prevent or treat patient-prosthesis mismatch. The latter usually requires aortic root enlargement $^{32}$ or reconstruction of the intervalvular fibrous body during double-valve replacement. ${ }^{33}$

\section{Limitations}

As a group, patients undergoing conventional doublevalve surgery were sicker, with a less favorable prognosis, than those undergoing less invasive surgery. When a propensity score was used to match patients, the comparison groups were intermediate in risk, and differences in most 

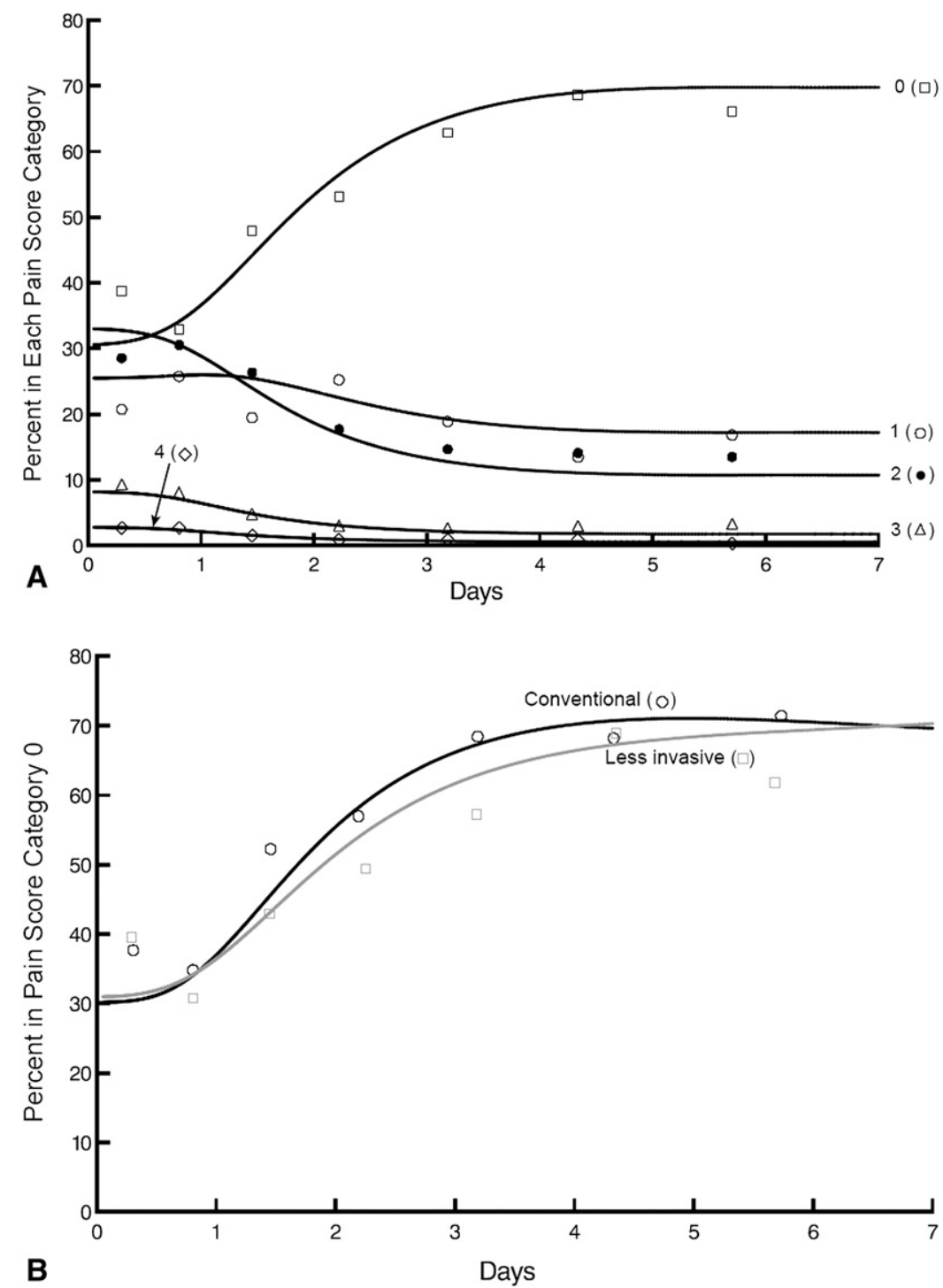

FIGURE 3. Temporal pattern of pain-score categories after double-valve surgery in propensity-matched patients. Symbols represent data grouped within time frames without regard for repeated assessment simply to provide crude verification of model fit. Solid lines are parametric estimates of percentage of patients in each category. A, All patients, all pain-score categories. B, Proportion of patients without pain (category 0) after less invasive surgery (squares) versus conventional sternotomy (circles).

outcomes appeared to be explained in large part by differences in patients' characteristics rather than surgical approach. We acknowledge that selection bias cannot be completely reversed by propensity-based methods and in this study cannot completely overcome distinct surgeon preferences. In addition, only $71 \%$ of all possible matches could be performed, because of unavailability of patients within portions of the propensity spectrum. However, the matches covered large parts of the spectrum. Because treatment was not masked, patients' self-reporting of pain scores might have been biased as well.

This is also a single-institution study, which limits its generalizability. Within this single-institution experience, multiple surgical teams performed the operation, and varia- tion among these teams exerts an unknown influence on postoperative results. Nevertheless, timing to extubation, spirometry, and pain scores would largely have been uninfluenced by potential surgeon biases because these were determined by anesthesiologists or routinely collected. Whether a larger series of patients with more power would have shown more benefits is unknown.

\section{CONCLUSIONS}

Less invasive surgery does not increase the risk of primary double-valve surgery. However, widespread acceptance of this technique requires further advances in technique and proof of benefits in propensity-matched patients, because a randomized trial appears unlikely. 


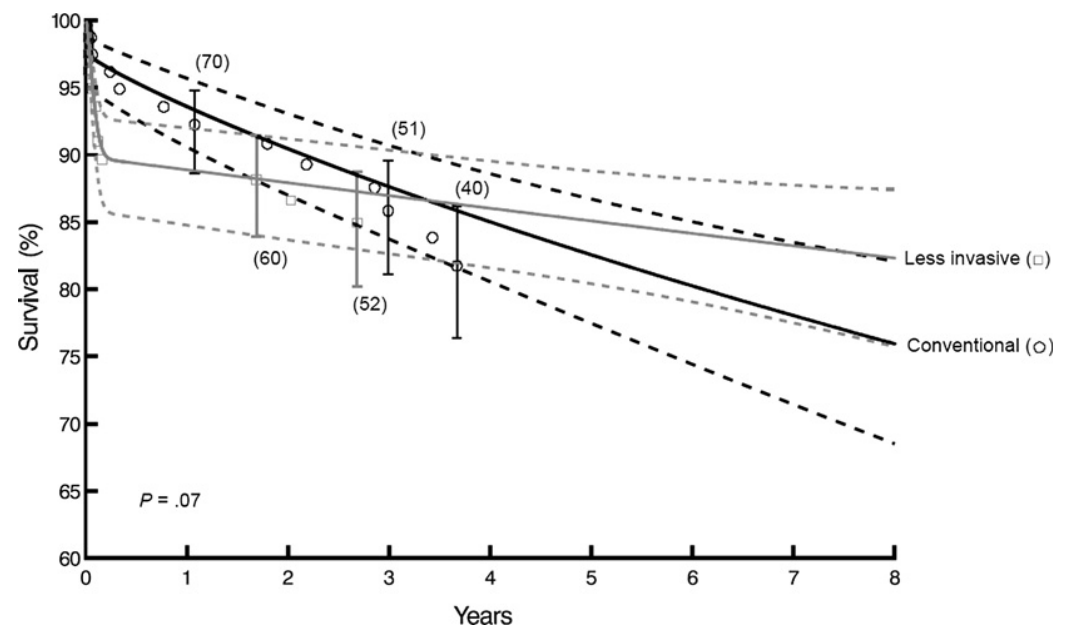

FIGURE 4. Survival after conventional double-valve surgery versus less invasive surgery in propensity-matched groups. Each symbol represents a death positioned actuarially, vertical bars represent $68 \%$ confidence limits, and numbers in parentheses represent patients remaining at risk. Solid lines are parametric estimates enclosed within dashed $68 \%$ confidence limits (equivalent to \pm 1 standard error).

We thank Karen Mrazeck and Jocelyn Piskach for data identification, Angela York for data management, and Tess Parry for editorial assistance.

\section{References}

1. Cosgrove DM 3rd, Sabik JF, Navia JL. Minimally invasive valve operations. Ann Thorac Surg. 1998;65:1535-9.

2. Svensson LG, Atik FA, Cosgrove DM, Blackstone EH, Rajeswaran J, Krishnaswamy G, et al. Minimally invasive versus conventional mitral valve surgery: a propensity-matched comparison. J Thorac Cardiovasc Surg. 2010;139: 926-32. e1-2.

3. Doty DB, Flores JH, Doty JR. Cardiac valve operations using a partial sternotomy (lower half) technique. J Card Surg. 2000;15:35-42.

4. Cohn LH. Minimally invasive aortic valve surgery: technical considerations and results with the parasternal approach. J Card Surg. 1998;13:302-5.

5. Reichenspurner H, Detter C, Deuse T, Boehm DH, Treede H, Reichart B. Video and robotic-assisted minimally invasive mitral valve surgery: a comparison of the PortAccess and transthoracic clamp techniques. Ann Thorac Surg. 2005;79:485-91.

6. Svensson LG. Minimal-access "J" or " $\mathrm{j}$ " sternotomy for valvular, aortic, and coronary operations or reoperations. Ann Thorac Surg. 1997;64:1501-3.

7. Svensson LG, D'Agostino RS. Minimal-access aortic and valvular operations, including the "J/j" incision. Ann Thorac Surg. 1998;66:431-5.

8. Chitwood WR Jr, Wixon CL, Elbeery JR, Moran JF, Chapman WH, Lust RM. Video-assisted minimally invasive mitral valve surgery. J Thorac Cardiovasc Surg. 1997;114:773-82.

9. Schroeyers P, Wellens F, De Geest R, Degrieck I, Van Praet F, Vermeulen Y, et al. Minimally invasive video-assisted mitral valve surgery: our lessons after a 4-year experience. Ann Thorac Surg. 2001;72(suppl):S1050-4.

10. Cohn LH, Adams DH, Couper GS, Bichell DP, Rosborough DM, Sears SP, et al. Minimally invasive cardiac valve surgery improves patient satisfaction while reducing costs of cardiac valve replacement and repair. Ann Surg. 1997;226:421-8.

11. Grossi EA, Galloway AC, LaPietra A, Ribakove GH, Ursomanno P, Delianides J, et al. Minimally invasive mitral valve surgery: a 6-year experience with 714 patients. Ann Thorac Surg. 2002;74:660-4.

12. Mihaljevic T, Cohn LH, Unic D, Aranki SF, Couper GS, Byrne JG. One thousand minimally invasive valve operations: early and late results. Ann Surg. 2004;240: 529-34.

13. Banbury MK, White JA, Blackstone EH, Cosgrove DM 3rd. Vacuum-assisted venous return reduces blood usage. J Thorac Cardiovasc Surg. 2003;126:680-7.

14. Rosenbaum PR, Rubin DB. The central role of the propensity score in observational studies for causal effects. Biometrika. 1983;70:41-55.

15. Rubin DB. The design versus the analysis of observational studies for causal effects: parallels with the design of randomized trials. Stat Med. 2007;26:20-36.

16. Blackstone EH. Comparing apples and oranges. J Thorac Cardiovasc Surg. 2002; 123:8-15.
17. Breiman L. Bagging predictors. Machine Learning. 1996;24:123-40.

18. Bergstralh EJ, Konsanke JL. Computerized matching of cases to controls. Technical report no. 56. Department of Health Science Research. Rochester, Minn: Mayo Clinic; 1995.

19. Mannino DM, Buist AS, Petty TL, Enright PL, Redd SC. Lung function and mortality in the United States: data from the First National Health and Nutrition Examination Survey follow up study. Thorax. 2003;58:388-93.

20. Wong DL, Baker CM. Pain in children: comparison of assessment scales. Pediatr Nurs. 1988;14:9-17.

21. Bieri D, Reeve RA, Champion GD, Addicoat L, Ziegler JB. The Faces Pain Scale for the self-assessment of the severity of pain experienced by children: development, initial validation, and preliminary investigation for ratio scale properties. Pain. 1990;41:139-50.

22. Boyle CA, Decoufle P. National sources of vital status information: extent of coverage and possible selectivity in reporting. Am J Epidemiol. 1990;131:160-8.

23. Newman TB, Brown AN. Use of commercial record linkage software and vital statistics to identify patient deaths. J Am Med Inform Assoc. 1997;4:233-7.

24. Blackstone EH, Naftel DC, Turner ME Jr. The decomposition of time-varying hazard into phases, each incorporating a separate stream of concomitant information. J Am Stat Assoc. 1986;81:615-24.

25. Gillinov AM, Blackstone EH, White J, Howard M, Ahkrass R, Marullo A, et al Durability of combined aortic and mitral valve repair. Ann Thorac Surg. 2001;72:20-7.

26. Gillinov AM, Blackstone EH, Cosgrove DM 3rd, White J, Kerr P, Marullo A et al. Mitral valve repair with aortic valve replacement is superior to double valve replacement. J Thorac Cardiovasc Surg. 2003;125:1372-87.

27. Walther T, Falk V, Metz S, Diegeler A, Battellini R, Autschbach R, et al. Pain and quality of life after minimally invasive versus conventional cardiac surgery. Ann Thorac Surg. 1999;67:1643-7.

28. Grossi EA, Zakow PK, Ribakove G, Kallenbach K, Ursomanno P, Gradek CE et al. Comparison of post-operative pain, stress response, and quality of life in port access vs. standard sternotomy coronary bypass patients. Eur J Cardiothorac Surg. 1999;16(suppl 2):S39-42.

29. Unic D, Leacche M, Paul S, Rawn JD, Aranki SF, Couper GS, et al. Early and late results of isolated and combined heart valve surgery in patients $\geq 80$ years of age. Am J Cardiol. 2005;95:1500-3.

30. Turina J, Stark T, Seifert B, Turina M. Predictors of the long-term outcome after combined aortic and mitral valve surgery. Circulation. 1999;100:II48-53.

31. Remadi JP, Baron O, Tribouilloy C, Roussel JC, Al-Habasch O, Despins P, et al Bivalvular mechanical mitral-aortic valve replacement in 254 patients: long-term results-a 22-year follow-up. Ann Thorac Surg. 2003;76:487-92.

32. Okuyama H, Hashimoto K, Kurosawa H, Tanaka K, Sakamoto Y, Shiratori K Midterm results of Manouguian double valve replacement: comparison with standard double valve replacement. J Thorac Cardiovasc Surg. 2005;129:869-74.

33. De Oliveira NC, David TE, Armstrong S, Ivanov J. Aortic and mitral valve replacement with reconstruction of the intervalvular fibrous body: an analysis of clinical outcomes. J Thorac Cardiovasc Surg. 2005;129:286-90. 
Variable

\begin{tabular}{|c|c|}
\hline \multicolumn{2}{|l|}{ Preoperative category } \\
\hline Demographic & Age $(\mathrm{y}), *$ sex, ${ }^{*}$ weight $(\mathrm{kg})$, height $(\mathrm{cm})$, body surface area $\left(\mathrm{m}^{2}\right)$, body mass index $\left(\mathrm{kg} \cdot \mathrm{m}^{-2}\right)^{*}$ \\
\hline Symptoms & New York Heart Association functional class (I-IV)* \\
\hline Ventricular dysfunction & Previous myocardial infarction,* degree of left ventricular dysfunction, ${ }^{*}$ ejection fraction $(\%)$ \\
\hline Mitral valve pathology & Mitral valve regurgitation, ${ }^{*}$ mitral valve stenosis* \\
\hline Mitral valve disease & Rheumatic, ${ }^{*}$ degenerative, $*$ ischemic, ${ }^{*}$ congenital \\
\hline Aortic valve pathology & Aortic valve regurgitation, ${ }^{*}$ aortic valve stenosis* \\
\hline Aortic valve disease & Rheumatic,* degenerative* \\
\hline Other valve pathology & Tricuspid valve regurgitation* \\
\hline Coronary anatomy & $\begin{array}{l}\text { Left main trunk disease (\% stenosis), left anterior descending coronary artery system disease (maximum \% stenosis), } \\
\text { right coronary artery system disease (maximum \% stenosis), }{ }^{*} \text { left circumflex coronary artery system disease } \\
(\text { maximum \% stenosis)* }\end{array}$ \\
\hline Other cardiac comorbidity & Atrial fibrillation,* complete heart block,* ventricular arrhythmia* \\
\hline Noncardiac comorbidity & $\begin{array}{l}\text { Hypertension,* treated diabetes, peripheral arterial disease, }{ }^{*} \text { carotid disease, endocarditis, smoking, }{ }^{*} \text { creatinine } \\
\left.(\mathrm{mg} \cdot \mathrm{dL})^{-1}\right), * \text { blood urea nitrogen }\left(\mathrm{mg} \cdot \mathrm{dL}^{-1}\right),{ }^{*} \text { bilirubin }\left(\mathrm{mg} \cdot \mathrm{dL}^{-1}\right),{ }^{*} \text { hematocrit }(\%)^{*}\end{array}$ \\
\hline Experience & Date of operation (years since January 1,1995$)^{*}$ \\
\hline \multicolumn{2}{|l|}{ Intraoperative } \\
\hline Mitral valve procedure & Repair,* replacement, prosthesis manufacturer \\
\hline Aortic valve procedure & Repair,* replacement, prosthesis manufacturer* \\
\hline Other procedure & Tricuspid valve repair* \\
\hline Surgeon & $\mathrm{A}, \mathrm{B}, \mathrm{C}, \mathrm{D}, \mathrm{E}, \mathrm{F}, \mathrm{G}, \mathrm{H}$ \\
\hline
\end{tabular}

*Variables included in the propensity model. 


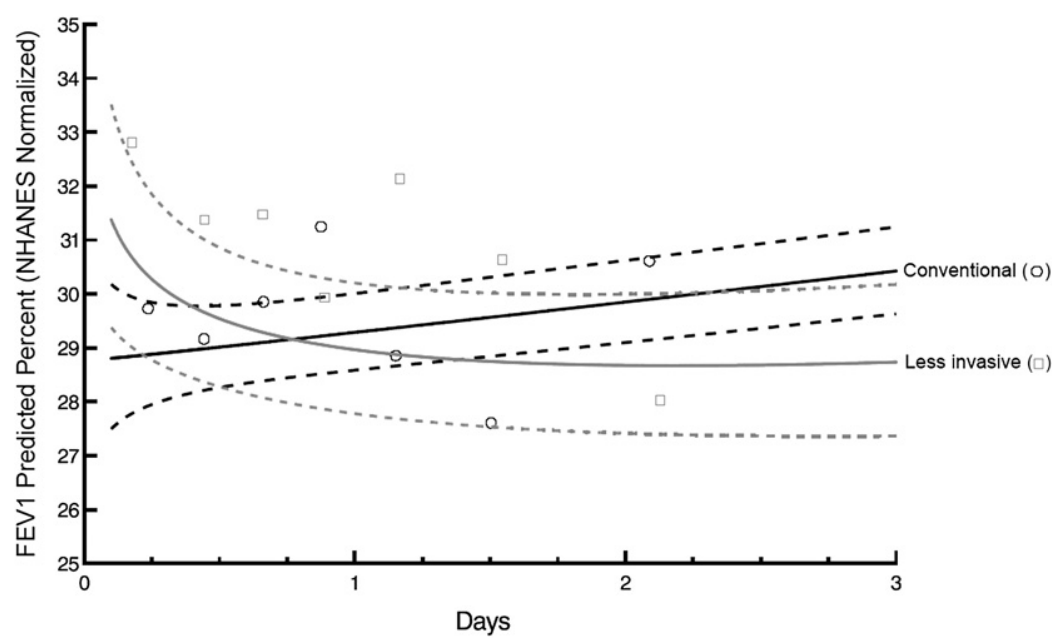

FIGURE E1. Risk-unadjusted depiction of temporal pattern of postextubation forced expiratory volume in 1 second $\left(F E V_{1}\right)$ as a percentage of predicted value after less invasive double-valve surgery and conventional surgery in overall groups. Solid lines are parametric estimates of temporal trend enclosed within dashed lines (68\% confidence limits, equivalent to \pm 1 standard error). Symbols represent data grouped within time frames without regard for repeated assessment simply to provide crude verification of model fit. 

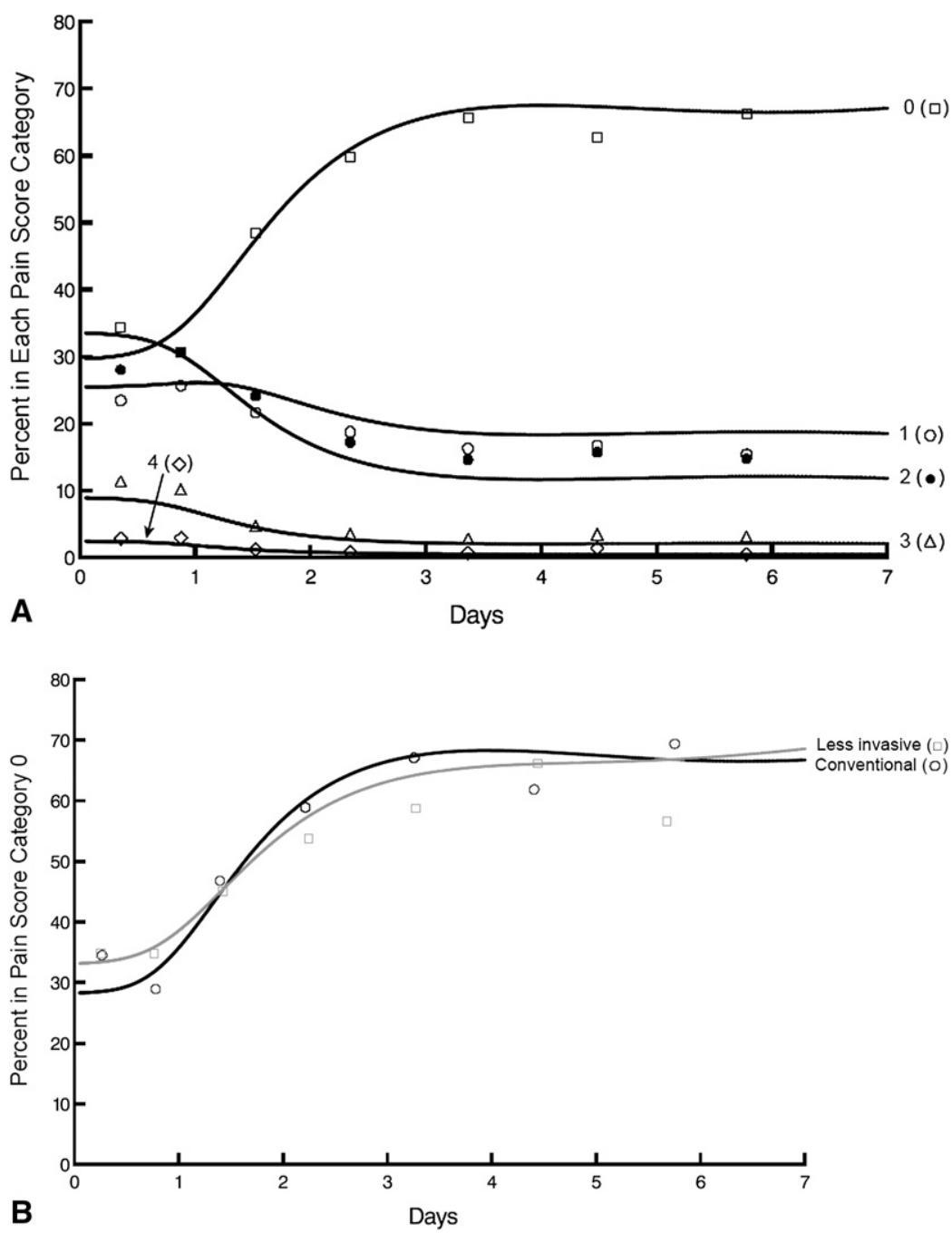

FIGURE E2. Risk-unadjusted estimate of temporal pattern of pain-score categories after double-valve surgery. Symbols represent data grouped within time frames without regard for repeated assessment simply to provide crude verification of model fit. Solid lines are parametric estimates of percentage of patients in each category. A, All patients, all pain-score categories. B, Proportion of patients without pain (category 0) after less invasive surgery (squares) and conventional sternotomy (circles). 


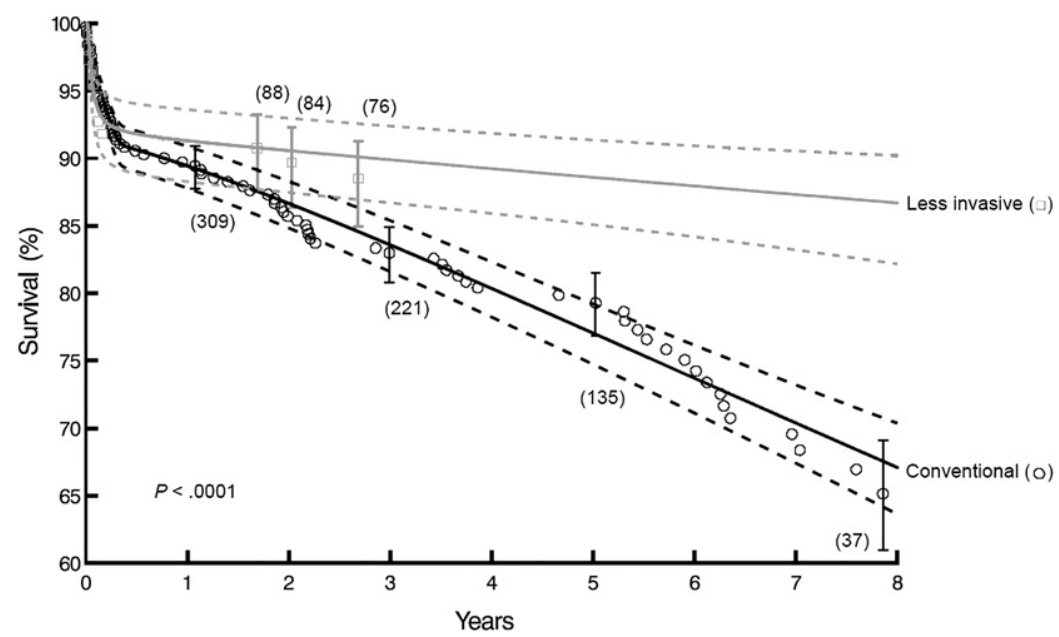

FIGURE E3. Risk-unadjusted estimates of survival after less invasive double-valve surgery versus conventional surgery. Each symbol represents a death positioned actuarially, vertical bars represent $68 \%$ confidence limits, and numbers in parentheses represent patients remaining at risk. Solid lines are parametric estimates enclosed within dashed lines ( $68 \%$ confidence limits, equivalent to \pm 1 standard error). 
TABLE E1. Factors associated with conventional versus less invasive approach

\begin{tabular}{lccc}
\hline \multicolumn{1}{c}{ Factor } & Coefficient \pm SD & P value & Reliability $(\%)^{*}$ \\
\hline Higher likelihood of conventional approach & & & .0008 \\
Higher BMI $\dagger$ & $2.6 \pm 0.78$ & $<.0001$ & 80 \\
COPD & $1.6 \pm 0.39$ & .003 & 95 \\
Severe TV regurgitation & $0.35 \pm 0.12$ & .01 & 49 \\
Higher NYHA functional class & $0.43 \pm 0.17$ & & 46 \\
Higher likelihood of less invasive approach & & & .0001 \\
Aortic valve repair & $1.4 \pm 0.29$ & .001 & 96 \\
More recent date of operation $\ddagger$ & $0.67 \pm 0.205$ & 82 \\
\hline
\end{tabular}

$S D$, Standard deviation; $B M I$, body mass index; COPD, chronic obstructive pulmonary disease; $T V$, tricuspid valve; NYHA, New York Heart Association. *Frequency of occurrence in 1000 bootstrap models. $\dagger(\mathrm{BMI} / 40)^{2}$, squared transformation. $\ddagger \operatorname{Ln}$ (interval from January 1, 1995, to date of operation), logarithmic transformation.

TABLE E2. Patient characteristics and operative details by surgical approach in unmatched group

\begin{tabular}{|c|c|c|c|c|c|}
\hline \multirow[b]{3}{*}{ Characteristic } & \multicolumn{5}{|c|}{ Unmatched } \\
\hline & \multicolumn{2}{|c|}{ Less invasive $(n=33)$} & \multicolumn{2}{|c|}{ Conventional $(\mathbf{n}=\mathbf{3 0 0})$} & \multirow[b]{2}{*}{$P$ value } \\
\hline & No.* & No. $(\%)$ or mean \pm SD & No.* & No. $(\%)$ or mean \pm SD & \\
\hline \multicolumn{6}{|l|}{ Demography } \\
\hline Female sex & 33 & $14(42)$ & 300 & $165(55)$ & .2 \\
\hline Age (y) & 33 & $58 \pm 11$ & 300 & $63 \pm 15$ & .02 \\
\hline BMI $\left(\mathrm{kg} \cdot \mathrm{m}^{-2}\right)$ & 33 & $25 \pm 3.3$ & & $28 \pm 6.4$ & .07 \\
\hline \multicolumn{6}{|l|}{ Cardiac comorbidity } \\
\hline NYHA functional class & 33 & & 300 & & $<.0001$ \\
\hline I & & $4(12)$ & & $26(8.7)$ & \\
\hline II & & $27(82)$ & & $128(43)$ & \\
\hline III & & $2(6.1)$ & & $108(36)$ & \\
\hline IV & & $0(0)$ & & $38(13)$ & \\
\hline LVEF $(\%)$ & 33 & $5.6 \pm 6.6$ & 236 & $48 \pm 15$ & .01 \\
\hline MV regurgitation & 33 & & 297 & & .01 \\
\hline Moderately severe (3+) & & $4(12)$ & & $103(35)$ & \\
\hline Severe $(4+)$ & & $22(67)$ & & $113(38)$ & \\
\hline MV stenosis & 33 & $8(24)$ & 283 & $87(31)$ & .4 \\
\hline $\mathrm{AV}$ regurgitation & 33 & & 286 & & .06 \\
\hline Moderately severe (3+) & & $13(39)$ & & $68(24)$ & \\
\hline Severe $(4+)$ & & $6(18)$ & & $71(25)$ & \\
\hline AV stenosis & 33 & $8(24)$ & 287 & $186(65)$ & $<.0001$ \\
\hline TV regurgitation & 33 & & 262 & & $<.0001$ \\
\hline Severe $(4+)$ & & $0(0)$ & & $28(11)$ & \\
\hline Atrial fibrillation/flutter & 33 & $5(15)$ & 300 & $69(23)$ & .3 \\
\hline \multicolumn{6}{|l|}{ Noncardiac comorbidity } \\
\hline Endocarditis & 33 & $2(6.1)$ & 300 & $15(5)$ & .8 \\
\hline COPD & 33 & $1(3)$ & 242 & $103(43)$ & $<.0001$ \\
\hline Hypertension & 31 & $10(32)$ & 283 & $153(54)$ & .02 \\
\hline Treated diabetes & 32 & $0(0)$ & 290 & $37(13)$ & .03 \\
\hline Creatinine $\left(\mathrm{mg} \cdot \mathrm{dL}^{-1}\right)$ & 32 & $0.7 / 0.9 / 1.02 \dagger$ & 296 & $0.7 / 1.0 / 1.5 \dagger$ & .002 \\
\hline
\end{tabular}

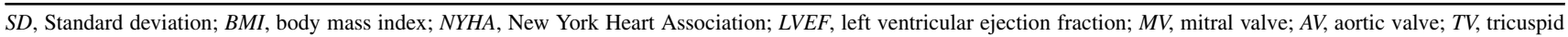
valve; $C O P D$, chronic obstructive pulmonary disease. *Patients with data available. $\dagger 15$ th $/ 50$ th $/ 85$ th percentiles. 